\title{
Cross-Cultural Communication And Dimensions: A Hybrid Analysis Of Horizontal And Vertical Individualist And Collectivist Tendencies Among African American And European American Management Students
}

\author{
Ephraim Okoro, Howard University, USA \\ Peter W. Cardon, University of Southern California, USA \\ Bryan Marshall, Georgia College and State University, USA \\ Otis Thomas, Bowie State University, USA
}

\begin{abstract}
This article describes research about horizontal and vertical individualism and collectivism (HVIC) among African American and European American university students. The survey is based on the work of Harry Triandis (1995), one of the seminal researchers of individualism and collectivism (I-C). The survey of attitude and scenario items, developed by Harry Triandis (1995), was administered to undergraduate management students in three universities in the Eastern and Southeastern United States. Many of the attitude and scenario survey items directly address preferred communication patterns. The findings are also interpreted in terms of situational preferences about I-C, including the following contexts: social events, workplace decisions, and group and work dynamics. The research is unique in that it measures four types of the I-C dimension: horizontal individualism, vertical individualism, horizontal collectivism, and vertical collectivism, as conceptualized by Triandis (1995). Furthermore, it emerges from the premise that cultures are neither strictly collectivist nor individualist; rather, cultures have profiles in which individualist tendencies are prominent in some circumstances whereas collectivist tendencies are emphasized in others. Also, this article provides findings that can easily be converted into training about cross-cultural similarities and differences. Related recommendations for future research and implications for teaching are provided.
\end{abstract}

Keywords: Intercultural Communication; Horizontal Individualism; Vertical Individualism; Collectivist; Individualist; European American; African American; Cultural Dimensions

\section{INTRODUCTION}

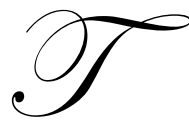

he individualism-collectivism (I-C) cultural dimension has become one of the most important constructs identifying cross-cultural variation in values, attitudes, and behaviors. In a recent review of I-C, House et al. (2004) identified over 1,400 articles devoted to individualism and collectivism. In a recent review of intercultural business and technical communication literature over the past 15 years, I-C was identified as the most frequently described cultural dimension. One of the most influential researchers and theorists of I-C is Harry Triandis, who grew up in the collectivist culture of Greece and moved to the individualist culture of the United States for his professional life. Triandis's research on I-C has expanded over many decades and is the basis for this research study (e.g., Triandis, 1967, 1988, 1993, 1995; Triandis \& Gelfand, 1998). 
Business communication instructors and scholars, particularly those who teach international business and intercultural business communication, should seek reliable information about cross-cultural business differences, particularly related to I-C. The work of Triandis (1995) offers promising potential for a more nuanced view of I-C tendencies within cultures, explaining individualist and collectivist tendencies as important in all cultures but prioritized under different circumstances. In other words, cultures are neither strictly collectivist nor individualist; rather, cultures have profiles in which individualist tendencies are prominent in some circumstances whereas collectivist tendencies are emphasized in others. His model is unique in that it measures four types of the I-C dimension: horizontal individualism, vertical individualism, horizontal collectivism, and vertical collectivism.

This paper examines Triandis's model in comparing and contrasting value and behavior preferences of African American and European American management students. This is particularly valuable since no known research has surveyed these two ethnic groups based on Triandis's (1995) complete survey instrument (attitude and scenario items). Furthermore, this article provides findings that can be converted easily into training about crosscultural similarities and differences between African American and European American university students.

\section{LITERATURE REVIEW}

In the seminal work on I-C, Individualism \& Collectivism, Triandis (1995) suggested that the I-C cultural dimension could best be reflected in four types: horizontal individualism, vertical individualism, horizontal collectivism, and vertical collectivism. Horizontal refers to an emphasis on equality, whereas vertical implies an emphasis on hierarchy. Singelis, Triandis, Bhawuk, and Gelfand (1995) made the following definitions of horizontal and vertical individualism and collectivism. Horizontal collectivism (HC) is "a cultural pattern in which the individual sees the self as an aspect of an in-group. . In this pattern, the self is interdependent and the same as the self of others. Equality is the essence of this pattern" (p. 244). Vertical collectivism (VC) is "a cultural pattern in which the individual sees the self as an aspect of an in-group, but the members of the in-group are different from each other, some having more status than others. . Serving and sacrificing for the in-group is an important aspect of this pattern" (p. 244). Horizontal individualism (HI) is "a cultural pattern where an autonomous self is postulated, but the individual is more or less equal in status with others" (p. 245). Vertical individualism (VI) is "a cultural pattern in which an autonomous self is postulated, but individuals see each other as different, and inequality is expected. . . Competition is an important aspect of this pattern" (p. 245).

Triandis explained that the four types of I-C can be interpreted as similar to various combinations of Hofstede's $(1980,2001)$ I-C and power distance dimensions. In other words, H-I is analogous to low power distance and high individualism, V-I to high power distance and high individualism, H-C to lower power distance and high collectivism, and V-C to high power distance and high collectivism. Since I-C and power distance were highly related $(\mathrm{r}=.67)$ in Hofstede's (1980) dataset, most cultures with high individualism have low power distance and vice versa. Thus, most cultures are predominantly H-I or V-C (Triandis, 1995).

One of the distinctions of Triandis's work on I-C is the notion of cultural profiles. He and his colleagues stated it this way:

Cultures are not pure; we assume that individuals exhibit each of these patterns [H-I, V-I, H-C, V-C] at different times or in different situations. . We propose that cultures differ in the emphasis and prevalence of the various orientations. For example, one culture may include individuals who use, across different situations, V-I 60\% of the time, $\mathrm{H}-\mathrm{I} 20 \%$ of the time, $\mathrm{V}-\mathrm{C} 15 \%$ of the time, and $\mathrm{H}$-C 5\% of the time, whereas the profile of another culture might be V-I 40\%, H-I 40\%, V-C 10\%, and H-C 10\%. . Obviously, we need to measure these tendencies to be able to identify their relative importance in each society. (Singelis, Triandis, Bhawuk, \& Gelfand, 1995, p. 246)

Triandis hypothesized that the American cultural profile would probably be about $40 \% \mathrm{H}-\mathrm{I}, 30 \% \mathrm{~V}-\mathrm{I}, 20 \%$ H-C, and 10\% V-C. Since the United States has a medium power distance score, Triandis (1995) considered American culture to have strong V-I tendencies. In fact, Triandis stated that Americans can be classified as a primarily vertical individualist culture in many circumstances, particularly for business circumstances (Triandis, 1995; Triandis \& Gelfand, 1998). 
Cross-cultural researchers have frequently proposed that African Americans are higher in collectivism and power distance than European Americans. However, a meta-analysis conducted by Oyserman, Coon, and Kemmelmeier (2002) concluded that there were no significant differences between African Americans and European Americans in terms of I-C. Yet another study, which employed various measures of I-C and did not treat $\mathrm{I}-\mathrm{C}$ as a bi-polar dimension, found that African Americans endorsed individualist and collectivist values more than European Americans (Coon \& Kemmelmeier, 2002). Thus, in terms of I-C values, differences between African Americans and European Americans are uncertain. In terms of practices, one known study has examined differences between the two groups using Triandis's scenario survey. Kapoor, Konsky, Blue, and Baldwin (2000) concluded that both groups exhibited similar I-C behavioral tendencies with the following order of preferences: $\mathrm{HI}>\mathrm{HC}>\mathrm{VI}>\mathrm{VC}$. However, they did not include attitude items in their survey.

\section{METHODOLOGY}

This study employed an instrument developed by Triandis (1995) to measure horizontal and vertical individualism and collectivism (HVIC) on an individual level. For attitude items, participants were asked to rate their agreement on a 9-point Likert scale. Each of attitude items and their corresponding I-C categories are presented in the Findings section. The scenario options were developed to focus on behaviors associated with HVIC. For each short scenario, respondents were given four alternatives of how to act in these situations. The four alternatives correspond to typical HI, VI, HC, and VC behaviors (Triandis, Chen, \& Chan, 1998). Several scenarios are described in the Findings section. A complete reading of the scenarios is available in the appendix of Triandis's (1995) work.

The attitude items were validated in a survey conducted among university students in two American universities $(n=267)$ with the following most common backgrounds: East Asian $(n=87)$, Western European $(n=$ 59), North European $(n=46)$, Pacific Islander $(n=45)$, and East European $(n=20)$ (Singelis, Triandis, Bhawuk, \& Gelfand, 1995). In only one study have the attitude and scenario items been administered together. Triandis and Gelfand (1998) administered the survey to 127 American university students. The correlations between attitude and scenario items ranged from small to large (HI: .11; VI: .51; HC: .41; VC: .29). The HI scenario items were negatively correlated with the VI scenario items $(r=-.50)$, and the $\mathrm{HC}$ attitude items were strongly correlated with the VC attitude items $(r=.50)$. Their study, however, did not compare differences between American ethnic groups.

For this study, we used the 14-item attitude scale adapted from Triandis's (1995) instrument by Sivada, Bruvold, and Nelson (2008). This modified version has better psychometric properties than the original 32 -item instrument and, due to fewer questions, increases the likelihood that respondents will be able carefully respond to the scenario items after responding to the attitude items. We report results from 18 of the original 31 scenarios developed by Triandis (1995). We selected the 18 scenarios that related to social events, group and work dynamics, and workplace decisions. T-tests were conducted to identify differences between the groups on the attitude items. Chi-square tests were conducted to identify differences between the groups for the scenarios.

The survey was administered to management students at three universities. One Eastern university is a traditionally African American university, and nearly all current students are African Americans. Two Southeastern universities involved in the study contain mostly European American management students. Altogether, 214 students completed the survey, including 125 African Americans (58 males, 67 females) and 89 European Americans (42 males, 47 females). Nearly all students were juniors and seniors, thus age differences were minor. We did not find significant differences between genders, therefore we simply report differences by ethnicity in the Findings section.

\section{FINDINGS}

As illustrated Table 1, there are some significant differences among HVIC attitudes. Overall, both African Americans and European Americans most strongly endorse $\mathrm{HI}$ attitudes $\left(M_{A A}=2.42 ; M_{E A}=2.87\right)$ and infrequently endorse $\mathrm{VC}$ attitudes $\left(M_{A A}=4.34 ; M_{E A}=3.89\right)$. Both groups somewhat strongly endorse $\mathrm{HC}\left(M_{A A}=3.79 ; M_{E A}=\right.$ 3.38) and VI attitudes $\left(M_{A A}=3.71 ; M_{E A}=3.64\right)$. European Americans more strongly endorsed both sets of collectivist (HC and VC) attitudes than African Americans did. African Americans, on the other hand, more strongly endorsed HI attitudes. There was no difference in VI attitudes between the two groups. 
In particular, European Americans far more strongly endorsed collectivist statements such as my happiness depends very much on the happiness of those around me; I would do what would please my family, even if I detested the activity; and I would sacrifice an activity that I enjoy very much if my family did not approve of it. African Americans far more strongly endorsed HI statements such as I enjoy being unique and different from others in many ways and I am a unique individual.

As illustrated in Table 2, there were essentially no overall differences between African Americans and European Americans. The total profile of HI-VI-HC-VC for African Americans and European Americans was 3223-30-15 and 32-21-33-14, respectively. Furthermore, when comparing totals for scenarios for given contexts (social events, group and work dynamics, and workplace decisions), few differences emerged between the groups. For both groups, HC behaviors were the predominant choices for social events; HI behaviors for group and work dynamics; and $\mathrm{HI}$ behaviors for workplace decisions. The most balanced profiles related to workplace decisions, however, with HI-VI-HC-VC profiles of 34-25-15-26 and 37-21-16-26.

Several significant differences emerged for particular scenarios. For example, European Americans were more likely to choose $\mathrm{HC}$ options for resolving conflicts and less likely to choose HI options. When purchasing art for the office, European Americans were more likely to choose the HI option, whereas African Americans were twice as likely to choose a VI option (see Figures 1 and 2 in the Discussion and Recommendations section).

As illustrated in Table 3, there was weak correlation between HVIC attitudes and related HVIC behaviors. In other words, there was not a significant correlation between HI attitudes and HI scenario choices (behaviors), VI attitudes and VI scenario choices, $\mathrm{HC}$ attitudes and $\mathrm{HC}$ scenario choices, and VC attitudes and VC scenario choices. Among the scenario items, HI scenario choices were most strongly and negatively correlated with VI scenario choices; VI scenario choices were strongly and negatively correlated with HC and VC scenario choices; and HC scenario choices were also strongly and negatively correlated with VC scenario choices.

\section{DISCUSSION AND RECOMMENDATIONS}

Contrary to existing expectations about differences between African Americans and European Americans, the African American sample in this study showed stronger endorsements of individualism (HI) than did European Americans, and the European American sample showed stronger endorsement of collectivism (HC and VC). There may be several explanations for this intriguing finding. First, as explained by Coon and Kemmelmeier (2001), many African Americans may have developed a particular desire to stand out as and be recognized as individuals as a reaction to feeling like they were defined by their ethnicity. Second, it is possible that the European American sample was not geographically representative - all students were from the Southeastern United States. It is possible that collectivist values are more prominent in this region given a stronger emphasis on traditional values in this part of the United States. Further studies that include students from various regions of the country could shed light on this.

Among the scenario options, there was little difference between African Americans and European Americans. Together, the HI-VI-HC-VC cultural profile was roughly 32-22-31-15. Triandis (1995) originally projected a profile of 40-30-20-10. Thus, our samples showed far stronger HC tendencies and far weaker VI profiles than projected by Triandis.

We are particularly disappointed with the weak correlation between HVIC attitude items and HVIC scenario choices (behavior). A major limitation of the extensive literature on individualism and collectivism is that the vast majority of studies examine values but not practices. Triandis (1995) developed scenario options in addition to attitude items to bridge this gap in identifying the link between values and practices. Since Triandis is considered one of the preeminent scholars on this subject (Hofstede, 2001), we expected that his propositions about the link between values and practices would be strong. If values do not effectively predict practices, much of our understanding of cross-cultural differences is in jeopardy. Therefore, our major recommendation for future intercultural business communication research is that it should include measures for values and practices to ensure that we better understand how they are related. Another recommendation is that future intercultural business communication research should better take into account context. In this study, certain types of HVIC were triggered 
under different circumstances. For example, both groups most frequently chose HC behaviors for social events but HI behaviors for workplace decisions. If it is triggers that best define various HVIC behaviors, business communication scholars could develop various business communication tasks and contexts into scenarios to examine when various HVIC behaviors are practiced most frequently and considered most appropriate.

We believe there is strong value in research that includes measures for behaviors/practices. Several decades of research about intercultural training and intercultural effectiveness have demonstrated the importance of critical incidents, stories or situations about contact between members of various cultures in which training participants are given various explanations for attributions and behaviors. Invariably, the ability to identify the most correct explanations has been related to intercultural effectiveness (Herfst, van Oudenhoven, \& Timmerman, 2008). One limitation of critical incidents, however, is that the appropriate explanations are based on the judgments of a majority of experts. Training participants do not hear the voice of cultural members nor are they aware of minority opinions among experts. In other words, explanations are presented as monolithic - explanations that apply to all cultural members.

A promising form of cross-cultural training (which we have conducted in our business communication classes) is to present the range of responses that cultural members have in various situations. Students are able to identify dominant practices in the culture but also recognize the variability within cultures and extent to which practices are shared across cultures. Triandis's (1995) survey instrument is ideal for this exercise for two reasons. First, the format of the scenario items is suited to these exercises with four available options. Second, and most importantly, the options were chosen based on theoretically-driven differences in I-C. We know of no set of crosscultural critical incidents that are theoretically based in this manner.

From this survey, any of the findings can be directly converted into a critical incident. For our classes, we generally first describe the scenario and the choices that are provided. Then we show a figure illustrating how the two groups responded (similar to Figures 1 and 2 shown below). In figure form, students quickly identify differences and similarities between groups and thus recognize cultural-level differences yet also are able to recognize how many members of both groups choose similar choices. We then discuss possible reasons for differences, which is aided by alluding to the theoretical underpinnings of the various options. We also discuss how these results might apply to related circumstances. Students find this exercise interesting and engaging.

\section{CONCLUSION}

This study examined differences and similarities between African American and European American management students. The groups shared far more similarities than differences. Both groups most strongly endorse $\mathrm{HI}$ attitudes and are least supportive of VC attitudes. Surprisingly, European Americans showed more support for collectivist (HC and VC) attitudes, whereas African Americans showed more support for HI attitudes. In terms of practices (choices to scenario items), there is little difference between the groups on the vast majority of cases.

We concluded with a discussion of how the scenario items can be a theoretically-developed and data-driven method of providing students with cross-cultural critical incidents. We believe there is strong potential for using instruments such as Triandis's(1995) HVIC survey instrument to instruct students and training participants in a way that identifies cross-cultural differences yet does not obscure individual variation within cultures.

\section{AUTHOR INFORMATION}

Ephraim A. Okoro is an assistant professor of business communication and marketing at Howard University. His research interests probe the interface between intercultural communication and workforce diversity in the context of globalization. Address correspondence to Ephraim A. Okoro, Department of Marketing, School of Business, Howard University, 2600 - Sixth Street, NW, Washington, D.C. 20059; E-mail: eaokoro@ howard.edu.

Peter W. Cardon is an associate professor of clinical management and communication at the University of Southern California. His primary research interests relate to intercultural business communication, and his favorite professional activity is leading study abroad groups. Address correspondence to Peter W. Cardon, Center for 
Management Communication, Marshall School of Business, University of Southern California, Los Angeles, CA 90089; E-mail: pcardon@sc.edu.

Bryan Marshall is an assistant professor of information systems at George College and State University in Milledgeville, Georgia. His research interests relate to information systems management. Address correspondence to Bryan Marshall, J. Whitney Bunting College of Busienss, George College \& State University, 241 W. Hancock Street, Milledgeville, GA 31061; E-mail: bryan.marshall@gesu.edu.

Otis Thomas is an associate professor and chair, Department of Communications and Director of TV/Radio, Bowie State University, Bowie, Maryland. His primary research interests focus on mass and organizational communication. Address correspondence to Otis Thomas, Bowie State University, Department of Communication, Bowie, MD 20715; E-mail: othomas@bowiestate.edu.

\section{REFERENCES}

1. Coon, H. M., \& Kemmelmeier, M. (2001). Cultural orientations in the United States: (Re)examining differences among ethnic groups. Journal of Cross-Cultural Psychology, 32(3), 348-364.

2. Herfst, S. L., van Oudenhoven, J. P., \& Timmerman, M. E. (2008). Intercultural effectiveness training in three Western immigrant countries: A cross-cultural evaluation of critical incidents. International Journal of Intercultural Relations, 32, 67-80.

3. Hofstede, G. (2001). Culture's consequences: Comparing values, behaviors, institutions, and organizations across cultures (2nd ed.). Thousand Oaks, CA: Sage.

4. House, R. J., Hanges, P. J., Javidan, M., Dorfman, P. W., \& Gupta, V. (Eds.) (2004). Culture, leadership, and organizations: The GLOBE study of 62 societies. Thousand Oaks, CA: Sage.

5. Oyserman, D., Coon, H. M., \& Kemmelmeier, M. (2002). Rethinking individualism and collectivism: Evaluations of theoretical assumptions and meta-analyses. Psychological Bulletin, 128, 3-72.

6. Singelis, T. M., Triandis, H. C., Bhawuk, D. P. S., \& Gelfand, M. J. (1995). Horizontal and vertical dimensions of individualism and collectivism: A theoretical and measurement refinement. Cross-Cultural Research, 29(3), 240-275.

7. Sivadas, E., Bruvold, N. T., \& Nelson, M. R. (2008). A reduced version of the horizontal and vertical individualism and collectivism scale: A four-country assessment. Journal of Business Research, 61, 20121.

8. Triandis, H. C. (1967). Interpersonal relationships in international organizations. Journal of Organizational Behavior and Human Performance, 2, 26-55.

9. Triandis, H. C. (1988). Collectivism v. individualism: A reconceptualization of a basic concept in crosscultural social psychology. In G. K. Verma \& C. Bagley (eds.), Cross-cultural studies of personality, attitudes and cognition (pp. 60-95). London: Macmillan.

10. Triandis, H. C. (1993). Collectivism and individualism as cultural syndromes. Cross-Cultural Research, 27, 155-18.

11. Triandis, H. C. (1995). Individualism \& collectivism. Boulder, CO: Westview Press.

12. Triandis, H. C., Chen, X. P., \& Chan, D. K.-S. (1998). Scenarios for the measurement of collectivism and individualism. Journal of Cross-Cultural Psychology, 29(2), 275-289.

13. Triandis, H. C., \& Gelfand, M. J. (1998). Converging measurement of horizontal and vertical individualism and collectivism. Journal of Personality and Social Psychology, 74(1), 118-128. 


\section{APPENDIX 1}

Table 1: Results for HVIC Attitude Items

\begin{tabular}{|c|c|c|c|c|c|c|c|}
\hline & \multicolumn{2}{|c|}{$\mathrm{AA}(n=126)$} & \multicolumn{2}{|c|}{ EA $(n=89)$} & \multirow[b]{2}{*}{$d f$} & \multirow[b]{2}{*}{$t$} & \multirow[b]{2}{*}{$p$} \\
\hline & $M$ & SD & $M$ & $S D$ & & & \\
\hline \multicolumn{8}{|l|}{ Horizontal Individualism Items } \\
\hline $\begin{array}{l}\text { I enjoy being unique and different from others in many } \\
\text { ways. (15) }\end{array}$ & 2.26 & 1.78 & 2.78 & 1.31 & 212 & -2.33 & $.02 *$ \\
\hline I often do "my own thing." (18) & 2.89 & 2.01 & 3.19 & 1.57 & 211 & -1.19 & .24 \\
\hline I am a unique individual. (21) & 2.13 & 1.94 & 2.65 & 1.59 & 211 & -2.09 & $.04 *$ \\
\hline Total HI & 2.42 & 1.70 & 2.87 & 1.27 & 208 & -2.13 & $.04 *$ \\
\hline \multicolumn{8}{|l|}{ Vertical Individualism Items } \\
\hline $\begin{array}{l}\text { I enjoy working in situations involving competition with } \\
\text { others. (12) }\end{array}$ & 3.43 & 2.07 & 3.48 & 1.83 & 213 & -.20 & .84 \\
\hline Competition is the law of nature. (19) & 3.46 & 2.07 & 3.58 & 1.70 & 209 & -.47 & .64 \\
\hline $\begin{array}{l}\text { Without competition it is not possible to have a good } \\
\text { society. (26) }\end{array}$ & 4.29 & 2.25 & 3.85 & 2.09 & 211 & 1.44 & .15 \\
\hline Total VI & 3.71 & 1.67 & 3.64 & 1.58 & 207 & .31 & .76 \\
\hline \multicolumn{8}{|l|}{ Horizontal Collectivism Items } \\
\hline $\begin{array}{l}\text { My happiness depends very much on the happiness of } \\
\text { those around me. (2) }\end{array}$ & 5.23 & 2.36 & 3.69 & 1.80 & 211 & 5.20 & $.00 * *$ \\
\hline $\begin{array}{l}\text { The well-being of my co-workers is important to me. } \\
\text { (14) }\end{array}$ & 3.57 & 1.78 & 3.33 & 1.40 & 212 & 1.07 & .29 \\
\hline If a co-worker gets a prize I would feel proud. (20) & 3.50 & 2.10 & 3.81 & 1.55 & 210 & -.1 .16 & .25 \\
\hline I feel good when I cooperate with others. (28) & 2.82 & 1.77 & 2.67 & 1.29 & 211 & .674 & .50 \\
\hline Total HC & 3.79 & 1.30 & 3.38 & 1.08 & 205 & 2.433 & $.02 *$ \\
\hline \multicolumn{8}{|l|}{ Vertical Collectivism Items } \\
\hline $\begin{array}{l}\text { I would do what would please my family, even if I } \\
\text { detested the activity. (3) }\end{array}$ & 5.23 & 2.16 & 4.16 & 1.93 & 211 & 3.71 & $.00 * *$ \\
\hline $\begin{array}{l}\text { I usually sacrifice my self-interest for the benefit of my } \\
\text { group. (7) }\end{array}$ & 4.57 & 1.93 & 4.15 & 1.79 & 211 & 1.62 & .11 \\
\hline $\begin{array}{l}\text { Children should feel honored if their parents receive a } \\
\text { distinguished award. (17) }\end{array}$ & 2.13 & 1.76 & 2.52 & 1.65 & 213 & -1.64 & .10 \\
\hline $\begin{array}{l}\text { I would sacrifice an activity that I enjoy very much if my } \\
\text { family did not approve of it (24). }\end{array}$ & 5.47 & 2.16 & 4.79 & 2.00 & 212 & 2.36 & $.02 *$ \\
\hline Total VC & 4.34 & 1.27 & 3.89 & 1.19 & 208 & 2.57 & $.01 *$ \\
\hline
\end{tabular}

Note. $\mathrm{AA}=$ African Americans; EA = European Americans. ${ }^{*} p<.05 . * * p<.01$. 


\section{APPENDIX 2}

Table 2: Percentage of HVIC Scenario Options Chosen

\begin{tabular}{|c|c|c|c|c|c|c|c|c|c|c|}
\hline & \multicolumn{4}{|c|}{$A A(n=126)$} & \multicolumn{4}{|c|}{$E A(n=89)$} & \multirow[b]{2}{*}{$\chi^{2}$} & \multirow[b]{2}{*}{$p$} \\
\hline & HI & VI & $\mathrm{HC}$ & $\mathrm{VC}$ & HI & VI & $\mathbf{H C}$ & VC & & \\
\hline \multicolumn{11}{|l|}{ Social events } \\
\hline Paying for dinner (33) & 10 & 70 & 19 & 2 & 4 & 83 & 10 & 2 & 5.57 & .13 \\
\hline Inviting guests to home (36) & 6 & 16 & 72 & 6 & 2 & 20 & 71 & 7 & 1.99 & .58 \\
\hline Accepting invitations (37) & 24 & 17 & 37 & 22 & 30 & 8 & 47 & 15 & 7.09 & .07 \\
\hline Buying clothing for major social event (60) & 4 & 24 & 69 & 3 & 9 & 22 & 63 & 6 & 3.18 & .37 \\
\hline Social events totals & 11 & 32 & 49 & 8 & 12 & 33 & 48 & 7 & & \\
\hline \multicolumn{11}{|l|}{ Group and work dynamics } \\
\hline Organizing sports teams (34) & 28 & 16 & 39 & 17 & 20 & 22 & 40 & 18 & 2.19 & .53 \\
\hline Solving controversy in the workplace (41) & 71 & 15 & 9 & 5 & 66 & 15 & 11 & 8 & 1.34 & .72 \\
\hline Resolving a conflict (43) & 30 & 9 & 56 & 6 & 18 & 2 & 73 & 7 & 9.08 & $.03 *$ \\
\hline Choosing a business partner (46) & 36 & 60 & 4 & 0 & 42 & 48 & 10 & 0 & 4.79 & .19 \\
\hline Discussing travel plans (52) & 57 & 5 & 25 & 13 & 59 & 2 & 35 & 3 & 7.95 & $.05^{*}$ \\
\hline Dividing lottery winnings (53) & 13 & 17 & 54 & 16 & 11 & 25 & 55 & 9 & 3.32 & .35 \\
\hline $\begin{array}{l}\text { Having picture taken by famous } \\
\text { photographer (54) }\end{array}$ & 46 & 14 & 16 & 23 & 68 & 3 & 13 & 16 & 12.55 & $.01 * *$ \\
\hline $\begin{array}{l}\text { Managing conflict between management } \\
\text { and union (62) }\end{array}$ & 41 & 3 & 46 & 10 & 26 & 2 & 63 & 9 & 6.49 & .09 \\
\hline Group and work dynamics totals & 40 & 17 & 31 & 11 & 39 & 15 & 37 & 9 & & \\
\hline \multicolumn{11}{|l|}{ Workplace decisions } \\
\hline Buying art for office (38) & 44 & 35 & 8 & 13 & 58 & 18 & 15 & 9 & 10.21 & $.02 *$ \\
\hline Hiring an employee (42) & 60 & 25 & 2 & 13 & 65 & 17 & 2 & 16 & 1.99 & .58 \\
\hline $\begin{array}{l}\text { Distributing limited amenities in the } \\
\text { workplace (47) }\end{array}$ & 21 & 41 & 17 & 21 & 19 & 45 & 16 & 19 & .40 & .94 \\
\hline Allocating bonuses at work (48) & 13 & 6 & 26 & 55 & 13 & 7 & 19 & 61 & 1.44 & .70 \\
\hline Designing advertisements (55) & 44 & 35 & 6 & 16 & 44 & 25 & 18 & 13 & 9.22 & $.03 *$ \\
\hline $\begin{array}{l}\text { Most important factor for deciding } \\
\text { promotion (59) }\end{array}$ & 23 & 10 & 28 & 39 & 22 & 13 & 27 & 37 & .46 & .93 \\
\hline Workplace decisions totals & 34 & 25 & 15 & 26 & 37 & 21 & 16 & 26 & & \\
\hline Totals & 32 & 23 & 30 & 15 & 32 & 21 & 33 & 14 & & \\
\hline
\end{tabular}

Note. AA = African Americans; EA = European Americans. Bolded (and non-italicized) items indicate the choice was chosen by the majority of respondents. Bolded and italicized items indicate items chosen most frequently but not by a majority. ${ }^{*} p<.05$. $* * p<.01$. 


\section{APPENDIX 3}

Table 3: Correlations among HVIC Attitude and Scenario Items

\begin{tabular}{|l|c|c|c|c|c|c|c|}
\hline & $\begin{array}{c}\text { HI } \\
\text { Attitudes }\end{array}$ & $\begin{array}{c}\text { VI } \\
\text { Attitudes }\end{array}$ & $\begin{array}{c}\text { HC } \\
\text { Attitudes }\end{array}$ & $\begin{array}{c}\text { VC } \\
\text { Attitudes }\end{array}$ & $\begin{array}{c}\text { HI } \\
\text { Scenarios }\end{array}$ & $\begin{array}{c}\text { VI } \\
\text { Scenarios }\end{array}$ & $\begin{array}{c}\text { HC } \\
\text { Scenarios }\end{array}$ \\
\hline HI Attitudes & - & & & & & & \\
\hline VI Attitudes & $.30^{* *}$ & - & & & & & \\
\hline HC Attitudes & $.42^{* *}$ & $.29^{* *}$ & - & & & & \\
\hline VC Attitudes & $.19^{* *}$ & $.26^{* *}$ & $.43^{* *}$ & - & & & \\
\hline HI Scenarios & -.09 & $.18^{* *}$ & .12 & .06 & - & & \\
\hline VI Scenarios & .03 & -.09 & -.11 & -.13 & $-.50^{* *}$ & - & \\
\hline HC Scenarios & -.04 & -.05 & -.13 & -.03 & $-.24^{* *}$ & $-.39^{* *}$ & \\
\hline VC Scenarios & .13 & -.06 & .16 & .13 & -.27 & $-.27^{* *}$ & $-.37^{* *}$ \\
\hline
\end{tabular}

Note. $* p<.05 . * * p<.01$. 


\section{APPENDIX 4}

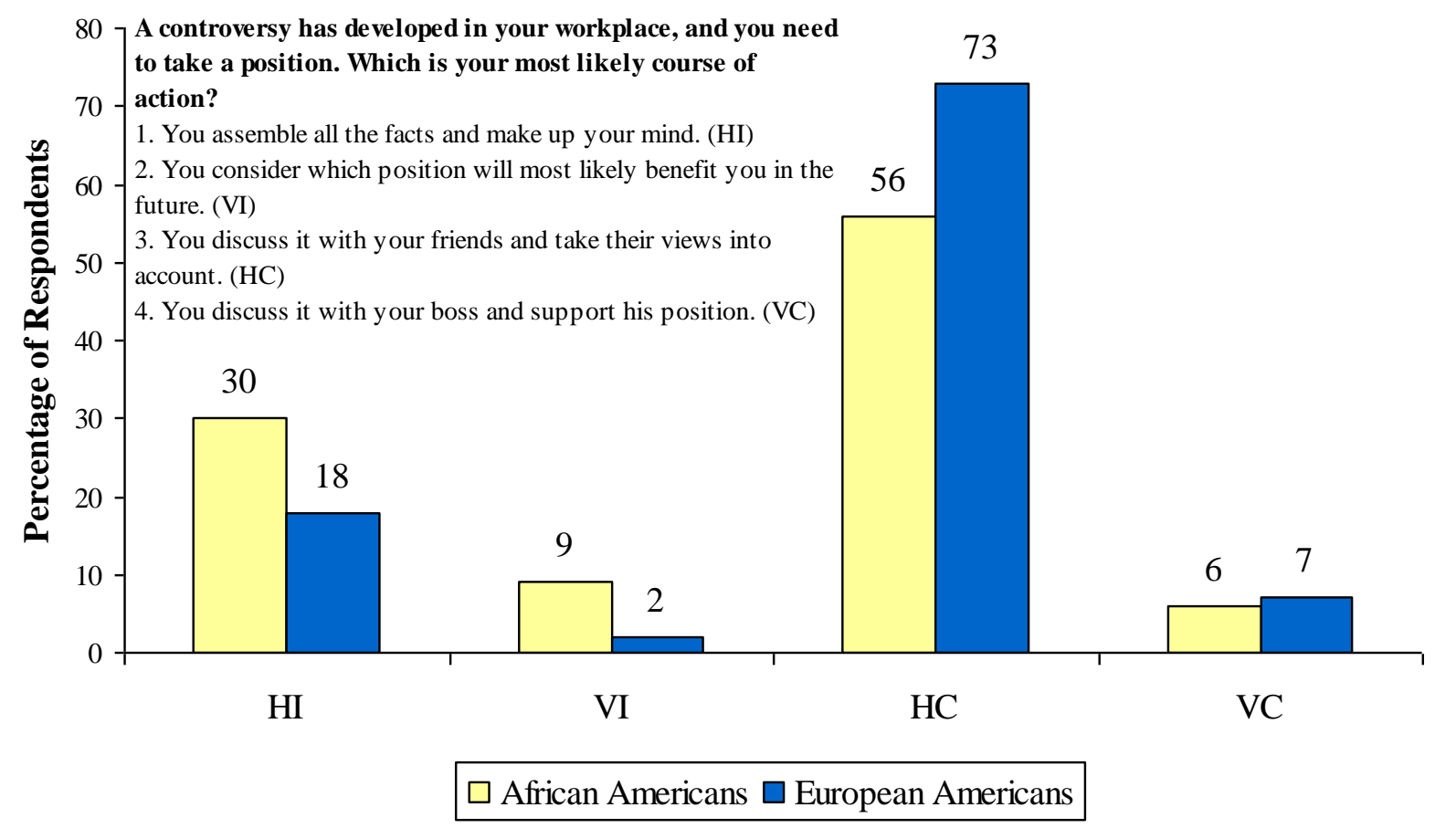

Figure 1. Results of workplace controversy scenario. 


\section{APPENDIX 5}

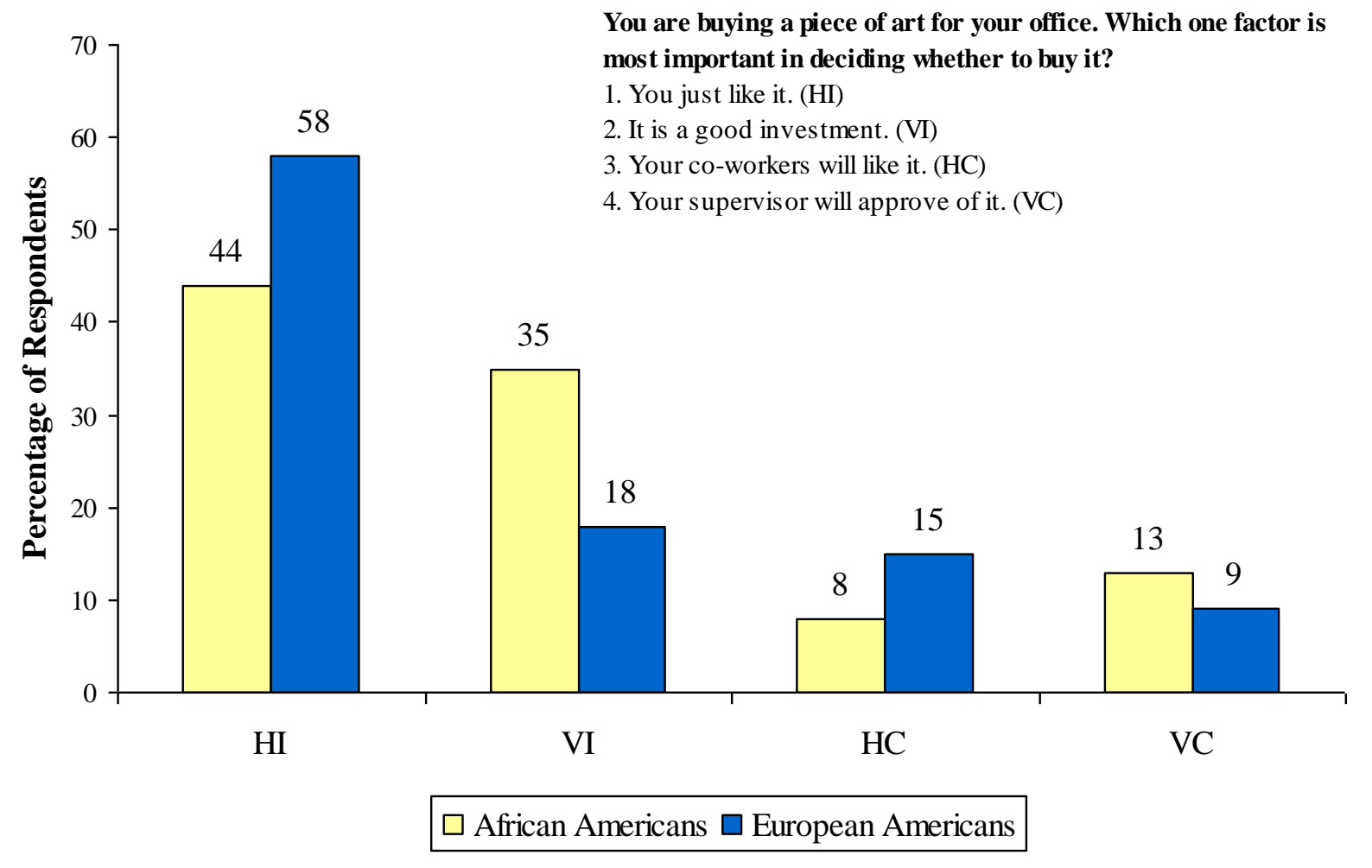

Figure 2. Results of purchasing art in the workplace scenario. 


\section{NOTES}

